\title{
Geodynamic risks of mining in highly stressed rock mass
}

\author{
Arkadiy Shabarov ${ }^{1}$, Anton Kuranov ${ }^{1 *}$, Anton Popov ${ }^{1}$ and Sergey Tsirel ${ }^{1}$ \\ ${ }^{1}$ Saint-Petersburg mining university, 199106, 2, 21st Line, St Petersburg, Russia
}

\begin{abstract}
The paper discloses that geological faults and phenomena associated therewith are the main risks of mining. The phenomena of fault activity and specific features of near-fault zones, determining their impact on the stability of mine workings and other man-made objects are discussed in detail. Different sections of faults are classified according to the degree and types of risk. The main attention is paid to the most stressed zones, where the fault is a closely spaced crack in the rock, characterized by specific strength and rock-bump hazard effect. The paper discloses that although mining operations change the stress-strain state of the massif, nonetheless, most of hazardous situations and geodynamic phenomena during excavation occur in tectonically stressed zones that already existed in the massif. In these areas, man-made overload during mining results to the formation of extremely stressed geodynamically hazardous zones. Thus, geodynamic zoning, which includes the identification of faults and block structure, assessment of their activity, as well as reconstruction of the stress-strain state of both the blocks and the near-fault zones, is the key method for assessing risks of geodynamic phenomena.
\end{abstract}

\section{Introduction}

In a broad sense, geodynamic hazard involves all the risks of disturbing engineering facilities, mine workings, buildings and structures, affecting human and animal health, etc., associated with dynamic processes in the top layer of the earth's crust - earthquakes, karst, erosion, large deformations, radiation, gas emanations, etc. Moreover, dynamic processes can be caused only by natural phenomena in the earth's crust and on the surface, as well as by the interaction of natural and man-made factors.

Many Russian researchers associate the increased accident rate first of all with disjunctive tectonic disturbances - faults [1-5].

According to the world practice, the attitude to the negative impact of faults (with the exception of seismogenic faults) varies greatly in different technical disciplines. In mining practice, faults are considered as a serious cause of accidents, especially of rock bursts, but not necessarily the main one.

As mentioned previously, it is near tectonic disturbances where the most of accidents of various types occurs. The strongest where during the development of the Khibin apatitenepheline deposits: a significant part of all hazardous geodynamic phenomena (rock bursts,

*Corresponding author: kuranov_ad@pers.spmi.ru 
micro-bursts, as well as rock falls in workings associated therewith) in underground workings are located at a distance of up to $20 \mathrm{~m}$ from faults of 4-5 ranks, as shown in figure 1.

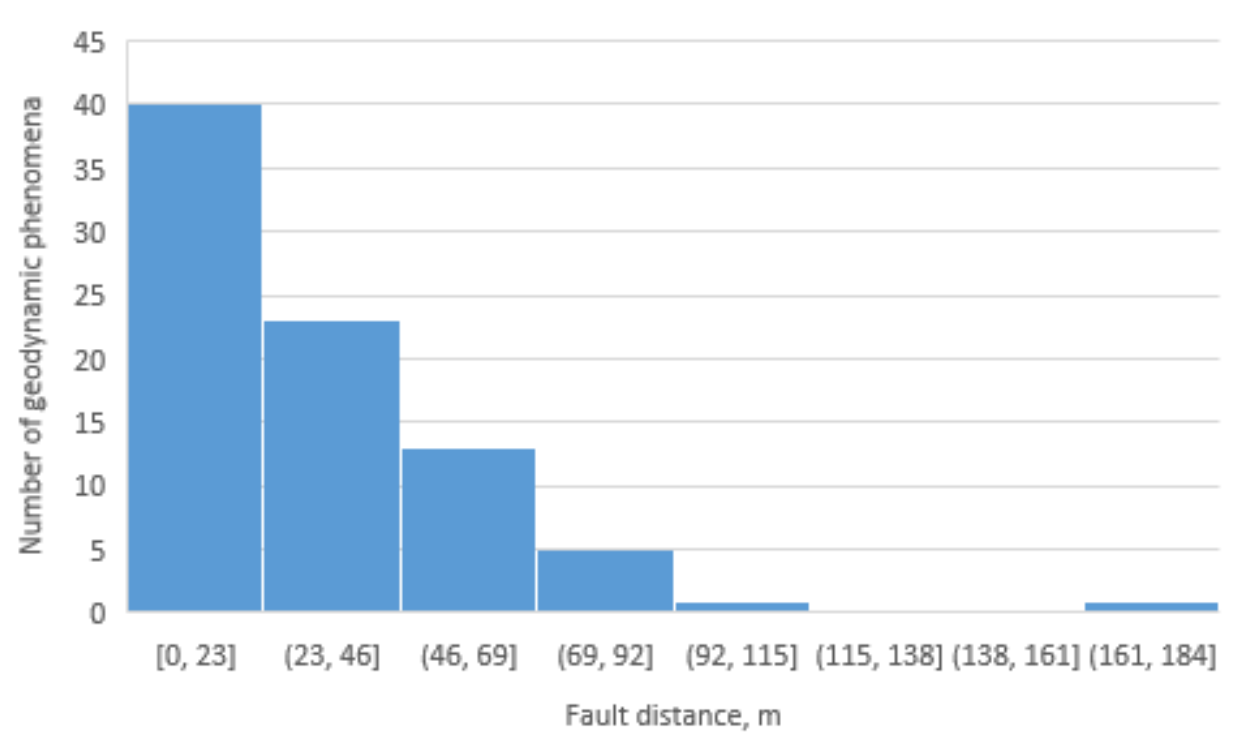

Fig. 1. Number of phenomena by fault distance for the faults of 3-5 ranks at the Kirovsky and Rasvumchorr mines

The key issues, this paper is devoted to, include studying the impact of faults on various engineering structures, as well as assessing and preventing risks associated with faults.

\section{Impact of faults on the risks of dynamic phenomena when performing underground mining}

The issues on correlation between dynamic phenomena of various types (rock bursts, coal and gas outbursts, rock falls, rock inrush, balm stones, etc.) have been discussed by a great number of researchers numerous times.

According to the studies carried out [1-5], the most intense tectonically stressed zones are confined to active discontinuous faults. Moreover, the stress level varies significantly along the length of faults. The most intense tectonically stressed zones are confined to fault closures and areas where the fault seam is a closely spaced crack (zones of type I in fig. 2). On the contrary, the areas containing the fault in the form of a crushing zone are unloaded, and the highly stressed zones are located far from the fault and have a lower intensity (zones of type II, in fig. 1). Diagrams of change in the stress state and rock mass properties in the near-fault zones of two types are shown in fig. 3. The nature of change in all indicators discloses a significant difference in the physical and stress state of the coal seam in the near-fault zones of the two types of discontinuous faults. The studies carried out made it possible to identify the mechanisms of forming sections of planes of discontinuous faults with different structure, as well as to determine their distinctive geological features (table 1). As a rule, zones of type I are confined to special sections of the fault - closures, changes in the angle of incidence or strike, bends, couplings with branch faults, intersections of layers of increased strength (including sandstone lenses), etc. 
Type 1

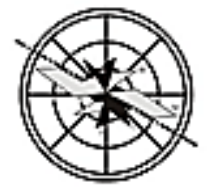

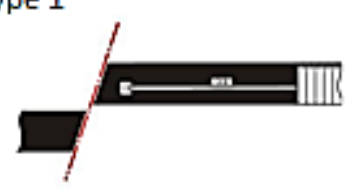

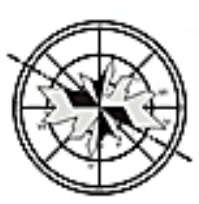

Type 2

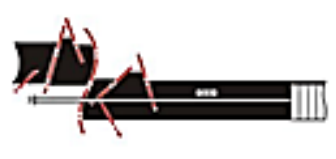

Fig. 2. Typical forms of tectonic disturbances of types I and II and associated systems of cracks

Stress distribution

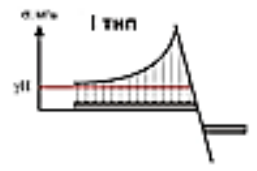

Drill cuttings yield

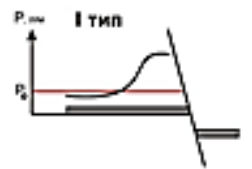

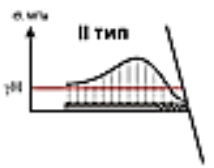

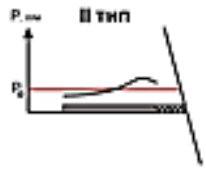

Gas release rate

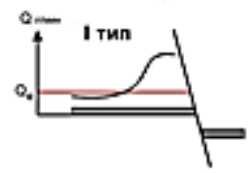

Electromagnetic emission

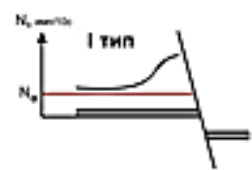

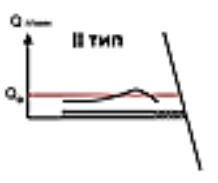

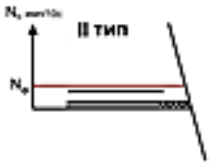

Fig. 3. Typical distribution of characteristics of the near-fault zones of types I and II

Table 1. Geological features of tectonic faults of types I and II

\begin{tabular}{|c|c|c|c|}
\hline \multirow{2}{*}{\multicolumn{2}{|c|}{ Distinctive feature }} & \multicolumn{2}{|l|}{ Section of tectonic fault } \\
\hline & & type I & type II \\
\hline \multicolumn{2}{|c|}{ Plane of fault displacement } & $\begin{array}{l}\text { Smooth, closed, closely } \\
\text { spaced crack }\end{array}$ & $\begin{array}{l}\text { Uneven wavy surface, set of } \\
\text { multiple faults }\end{array}$ \\
\hline \multicolumn{2}{|c|}{ Crushing zone } & Not pronounced or absent & $\begin{array}{l}\text { Present, modal width of } 0.1-0.4 \mathrm{~m} \text {, } \\
\text { reaches } 1-2 \text { or more meters }\end{array}$ \\
\hline \multicolumn{2}{|c|}{$\begin{array}{l}\text { Phenomena in the coal } \\
\text { seam (deposits) }\end{array}$} & $\begin{array}{l}\text { The crushed coal zone is } \\
\text { absent or falls within the first } \\
\text { centimeters. Increased density } \\
\text { and strength of coal }\end{array}$ & $\begin{array}{l}\text { There is a crushed coal zone with a } \\
\text { length of up to } 1.5-2 \mathrm{~m} \text {, frequently } \\
\text { in the form of an earthy mass }\end{array}$ \\
\hline \multicolumn{2}{|c|}{ Associated faults } & - & $\begin{array}{l}\text { Present, zone with a width of up to } \\
2.5-3 \text { amplitudes of fault } \\
\text { displacement }\end{array}$ \\
\hline \multicolumn{2}{|c|}{ Presence of filler } & - & $\begin{array}{l}\text { Present, as a rule, it is calcite in the } \\
\text { form of grease on the walls of } \\
\text { cracks, as well as veins. }\end{array}$ \\
\hline \multicolumn{2}{|c|}{ Additional crack systems } & $1-2$ or absent & 3-4 and more \\
\hline \multirow{7}{*}{ 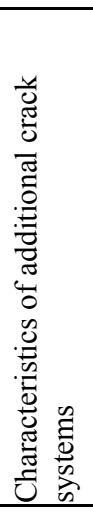 } & $\begin{array}{l}\text { Orientation of } \\
\text { additional crack } \\
\text { systems }\end{array}$ & $\begin{array}{l}\text { Parallel to the plane of fault } \\
\text { displacement }\end{array}$ & Chaotic \\
\hline & Opening & Closed, closely spaced & Open \\
\hline & Shape & Straight & Wavy \\
\hline & Length & $\begin{array}{l}\text { Long, cross the entire } \\
\text { formation (deposit) or its part }\end{array}$ & $\begin{array}{l}\text { Short (up to } 3-5 \mathrm{~cm} \text { ), limited by } \\
\text { separate interlayers }\end{array}$ \\
\hline & Surface & Smooth & Rough, wavy \\
\hline & $\begin{array}{l}\text { Presence of } \\
\text { filler }\end{array}$ & - & $\begin{array}{l}\text { Present, calcite, pyrite grease, clay } \\
\text { gouge }\end{array}$ \\
\hline & $\begin{array}{l}\text { Presence of } \\
\text { slickenline }\end{array}$ & Present & Usually absent \\
\hline
\end{tabular}


Intense tectonically stressed zones are associated not only with single faults, but also with fault systems. The most hazardous structures, forming intense tectonically stressed zones first of all include echelon-like fault systems, convergence of faults, branching at acute angles $\left(10^{\circ}-15^{\circ}\right)$, wedge-shaped structures.

Incompletely formed or being forming discontinuous faults, first of all, flexures, as well as sharp changes in the thickness of the mineral deposit (seam) and the layers of enclosing rocks are often among rather hazardous geological disturbances, characterized by sharply increased or sharply reduced stresses.

Although mining operations significantly change the stress-strain state of the massif, nonetheless, most of hazardous situations and geodynamic phenomena during excavation occur in tectonically stressed zones already existed in the massif. It is in the area of tectonically stressed zones that man-made overload during excavation (bearing pressure) results to the formation of extremely stressed geodynamically hazardous zones. Moreover, the process of such zones formation, their number, size and hazard level depends on the tension of tectonic blocks and the type of discontinuous faults.

Within the zone of excavation, owing to a man-made impact, the stresses in tectonically stressed zones increase by $30-80 \%$.

When the coal long-wall approaches the tectonically stressed zone of type II, a different pattern takes place. An increased tension was observed at a distance of 20 to $10 \mathrm{~m}$ before the $\mathrm{P}_{3}$ fault, then all the indicators recorded unloading of the formation; the face entered the fault zone, even if this fault zone was not significantly pronounced during the preliminary development. The data presented above was obtained during long-term studies performed at the Vorkuta deposit [9-10].

Nonetheless, entering the fault zone should not be considered safe. Thus, when performing numerical simulation, the $S R F$ (Strength Reduction Factor) is widely used as a criterion of tension [6]. According to [6], the hazard level (fig. 4) in unloaded zones can be compared with the hazard level of stressed zones with a ratio of $\sigma_{1}$ with a uniaxial compressive strength in the range of $0.2-0.3$. Actually, it is pronounced in the form of a decrease in the stability of the roof of the workings, vertical exposures (including a longwall face), rock inrush, balm stones, etc., increased gas release, as well as sudden outbursts of gas, coal and rock from the walls of the workings. A special hazard in such zones is associated with increased water inflows, which can result to siltation of a long-wall and the risk of losing expensive mining equipment.

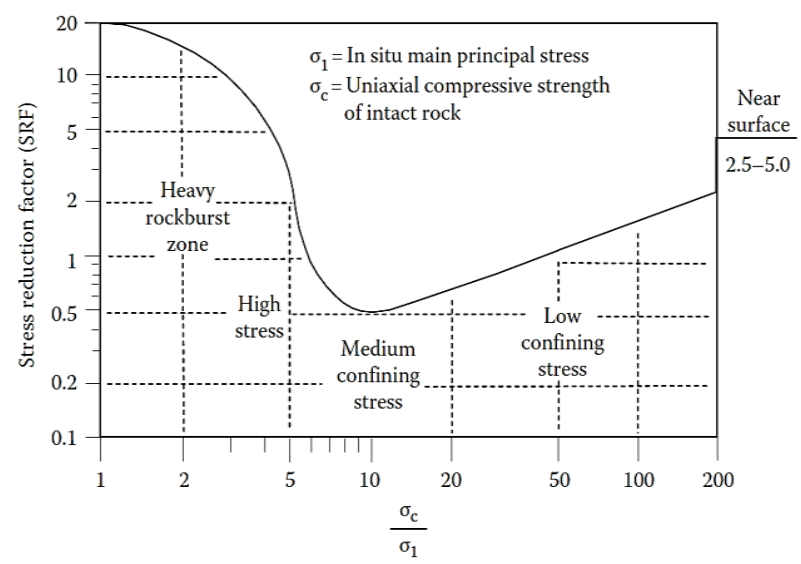

Fig. 4. SRF: ${ }{ }_{c}$-ultimate compressive strength in the sample; $\sigma_{1}$ - maximum stresses in the massif, enclosing the working [6] 


\section{Geodynamic zoning}

The prediction and prevention of problems associated with discontinuous faults is based on the thorough allocation of faults, block structure of the massif and its stress state assessment.

In geological practice, the main methods for identifying discontinuous faults include structural imaging based on drilling data and areal geophysical surveys. However, the use of these methods is insufficient for identifying potentially hazardous zones associated with discontinuous faults. The set of methods for allocating active faults, reconstructing the actual block structure, assessing its stress state and geodynamic risks for various man-made objects includes geodynamic zoning.

When performing geodynamic zoning, it was assumed that the earth's crust and its surface represent a hierarchical fractal structure, traditionally divided into 7-10 scale levels (ranks). According to "Methodological recommendations for assessing the tendency of ore and non-ore deposits towards rock bursting" [8], approved by the Order of the Federal Service for Environmental, Technological, and Nuclear Supervision, there are 9 levels. The classification of faults by size is closely related to the classification of the sizes of tectonic blocks [7].

Thus, having analyzed the results of geodynamic zoning provided by different authors it is possible to conclude that the blocks of the main rank for this model, as a rule, in many respects, represent actual geological structures. Despite the ambiguity and some artificiality of the block structure reconstruction during geodynamic zoning, it is deemed to be a convenient and useful tool for preliminary engineering-geological and geomechanical analysis of geodynamic risks.

The practice of performing geodynamic zoning has shown that interpretation of aerial and satellite images, as well as surface topography analysis (morphometric method) are the two most efficient approaches. The two approaches, namely, manual processing of images and computer processing of images using various software are used for the interpretation of surface images.

\section{Manual interpretation of aerial and satellite images}

When performing manual processing, there is a major probability of errors, as well as making subjective unreasonable decisions. Maps built by inexperienced geologists vary greatly when compared to each other.

The methodology of manual interpretation of aerial and satellite images, to the first approximation, consists in determining tectonogenic lineaments as faults, pronounced in the current landscape of the area. Non-cemented crushing zones of bedrock, interrupting the elastic properties of rock mass, regardless of the value and presence of the apparent amplitude of displacement of separated or adjacent tectonic blocks, are considered as such faults. These faults as non-cemented crushing zones appear in the landscape and surface topography, due to their anomalous, compared to undisturbed sections of the massif, first of all mechanical and hydrogeological, as well as geophysical, geochemical and other characteristics. The bedrock in these zones is prone to erosion-denudation destruction, and the crushing zones serve as migration channels for subsoil and ground water, which, through vegetation, predetermines their anomalous narrow-band appearance in the natural landscape on aerial and satellite images.

The general pattern and configuration of interpreted man-made lineaments, as well as the hypsometric position of the geodynamic blocks separated by them and their comparison with the topographic map, allow providing morphological classification of the allocated corresponding faults. 


\section{Computer interpretation of aerial and satellite images.}

Another more formalized approach is based on the use of software products, which can significantly increase the efficiency of geodynamic zoning and ensure the repeatability of its results [9-11]. This approach includes the following steps.

1. A digital elevation model, built on the basis of remote sensing data of the earth's surface, is used as a source data for the geodynamic analysis of the tectonic massif. Currently, there are several software products that allow using this technology [9-11].

2. Computer lineament analysis of maps from digital elevation model. When studying the features of lineament tectonics, software units with the operation algorithm based on the theory of generalized Hough transform, are used [12]. The advantage of the Hough method before other methods of allocating lineaments lies in the fact that when allocating linear segments, it does not rely on the assumption of their (segments) mandatory connectivity.

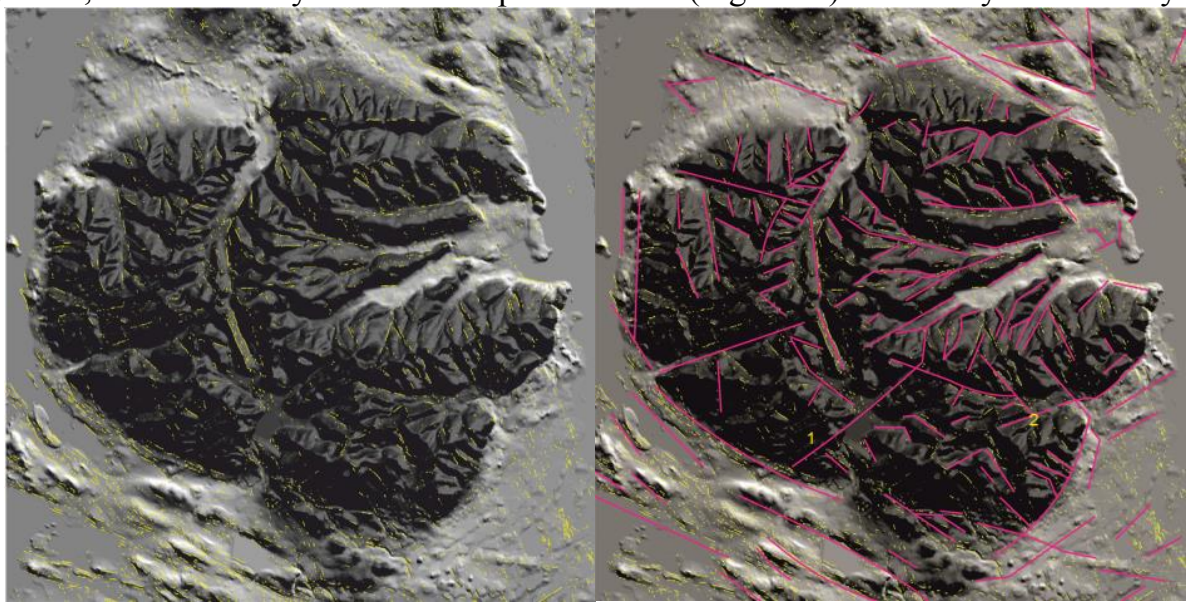

Fig. 5. The result of computer lineament analysis of the map from the digital elevation model of the Khibiny massif.

Figure 5 illustrates an example of computer interpretation of the digital elevation model obtained using satellite images. Lineaments, selected algorithmically via LESSA software are shown with yellow dashed lines. The expert interpretation of the results of computer lineament analysis of the map from the DEM of the Khibiny massif assumed the allocation of lineaments during the expert analysis, as shown with red lines. Partial automation of doing such work renders possible to significantly reduce the time needed for the work execution, as well as to avoid errors associated with the subjectivity of thinking of the work performer.

The correlation of the faults, established by the surface topography, with the discontinuous faults allocated in the crystalline basement and sedimentary cover, first of all, specifies the depth of the fault expansion and the impact of active subcrustal processes on the fault mobility.

Tectonophysical factors to a great extent characterize the geomechanical conditions and the activity of interaction of blocks, separated by the allocated faults. In this case, the orientation of the axes of the main stresses in different regions changes, and the ratio of stresses magnitudes changes as well. Due to unequal component stresses, significant shear stresses occur. Therefore, faults that fall into the plane of action of maximum shear stresses are potentially more mobile; they are to major extent characterized by the tendency towards relative displacement of the wings. Such planes are inclined to the axes of maximum and minimum normal stresses at an angle of $45^{\circ}$.

Faults, perpendicular to the axis of minimum compression, on which the greatest tensile strains of maximum tension are observed, even under conditions of all-round compression, 
may experience not shear displacement of the wings, but their moving away from each other with the formation of a weakened zone. Faults, perpendicular to maximum stresses, have the tendency towards the most contrasting tectonically stressed zones. If, for example, $\sigma_{\max }$ acts in the horizontal plane and amounts to $1.5 \gamma \mathrm{H}$, then in case when a half of its area contacts, due to unevenness of the planes of fault displacement, concentration of stresses at the contact points will reach $3 \gamma \mathrm{H}$.

Seismic phenomena witness in favor of the activity of faults. The higher the seismicity, the deeper spreads the zone of rocks that came into an extremely stressed state. The presence of seismic phenomena in the zone affected by this fault indicates that dynamic movement occurs along this fault or an increase in the length of the fault, the formation of branch faults, or other phenomenon is observed.

\section{Assessment of the geodynamic state of rock mass with a block structure, formed by discontinuous faults}

Since the activity of faults and the geodynamic risk, associated with the faults, can be determined by wide range of factors, the assessment of the stress-strain state have been and remains the basis of the numerical risk assessment. As shown above, during underground mining, it is stresses that primarily determine the risks of rock bursts and other hazardous phenomena. For ground and semi-buried structures, it is important to identify the most unloaded sections of discontinuous faults, especially unstable zones and channels of fluid flow.

The natural stress field is the result of interaction between all elements of the block structure. Mutual displacement and deformation of blocks determine the stress state of undeveloped rock mass. In actual practice, it is impossible to take into account all blocks of various ranks, and for a specific case it is sufficient to consider only blocks comparable to the typical scale of the problem being solved.

However, it should be understood, that the experimental data on stresses and strains beyond the boundaries of the estimated zone are also affected by local inhomogeneity (block structures of different ranks) and can give the wrong idea about the general characteristics of regional stress fields.

The validity of the conclusions, reliability of the outcomes and recommendations resulting from the calculations, to a major degree depends on the extent to which the actual properties of rocks, the conditions at their boundaries and contacts are accounted for [12]. In the mathematical characterization, these properties are represented by models of medium, considering the essential features of the rocks that determine their behavior during mining operations.

The construction of a general model, which would take into account all the key properties of rocks, determined through the experiments, is inexpedient, because, to date, there are either no analytical methods, capable of considering them, or the level of computing hardware does not allow implementing the existing methods for such sophisticated models of medium. Moreover, excessive details in the model of medium, without entering significant amendments into the calculated parameters, will result to a significant increase in time required for their determination. Thus, the efficiency in obtaining the required data will be missing. Proceeding from the above, for the most calculations of the stress state of rock mass, it seems reasonable to use a combination of linear-elastic and plastic media models.

The complexity of searching for the solutions for these and other academic issues results to a disagreement among those skilled in the art concerning the optimal method of conducting calculations [12]. In geomechanics of this type, problems are solved by three main methods: the finite element method FEM [26], the boundary element method BEM 
[16-19], or the discrete element method DEM [13-15]. Combined analysis, including the methods of limit equilibrium and finite elements, is implemented, for example, via GEOSLOPE software [21]. Other hybrid numerical models, used in geomechanics, combined the BEM/FEM, BEM/DEM methods, and FLAC3D/PFC3D [22]. Hybrid software with the procedure of rearranging elements, such as ELFEN [23], has been successfully used for simulation of intense fracturing in underworked rocks and during roof collapse [24].

\section{Example of using geodynamic data during field development}

By way of example, let us consider the use of data, obtained during geodynamic zoning and updated on a regular basis during geodynamic monitoring, in coalmines of the Vorkuta coal basin, Leninsk coal basin, as well as at apatite-nepheline deposits of the Khibiny massif.

Coal seams of the Vorkuta deposit are being developed at four mines independently of each other (fig.7). Minefields are located on adjacent areas, resulting in the mutual influence of geomechanical and geodynamic processes, induced by mining. With this requirement taken into account, in mining projects and plans, it is expedient to assess the geodynamic state of rock mass at the regional level, whereon conceptual solutions on cutting the remaining reserves of the field into extraction blocks, determining their boundaries and the reserves extraction procedure, proceeding from the requirements of economic feasibility and geodynamic safety, are determined.

In view of the above, the issue of reliable predicting the location of discontinuous faults, determining the zone affected by faults, the amplitude of displacement along the fault plane, the sign and type of the fault in the deep part of the field, remains a matter of urgency. To this end, traditional methodological approaches to geodynamic zoning were supplemented by three-dimensional simulation of the basic structural elements of the field, as well as visual examination in the underground space.

Coal seams bedding in the southern part of the trough is complicated by high-ranked folds, frequently forming flexures, with a drop on the wings of up to $45^{\circ}$. The entire northwestern part of the minefield is characterized as a zone of development of folding of the second and third ranks, taking into account that the entire trough refers to first-ranked plicatives. Substantially, this section of the minefield is also the bottom, central part of the entire trough. Moreover, based on the analysis of the results of geodynamic simulation and geological and structural simulation, the boundaries of tectonically stressed zones in the large block structures of the Vorkuta deposit were determined.

In case of discontinuous faults being the boundary of the tectonically stressed zone, the zone affected by the discontinuous fault, pronounced in the change of natural rock bedding, is allocated everywhere. When approaching the plane of the fault displacement, such phenomena as crumpling, micro-folding, lithological domain thickness variation, swelling and pinching of the formation, partial or complete lensing of the most plastic rocks, boudinage occur in the zone of influence. The formation of fracturing and crushing zones takes place (figure 6).

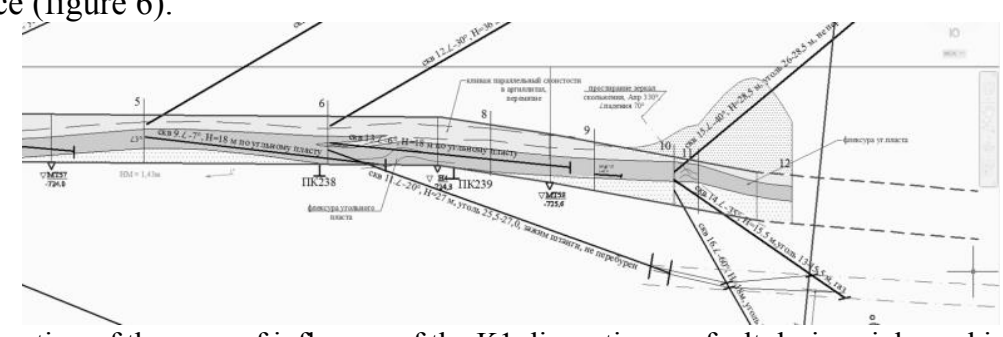

Fig. 6. formation of the zone of influence of the K1 discontinuous fault during sink workings opening it (an excerpt from the document for the working of KS-623s seam Forth, provided by the chief geologist of the Zapolyarnaya mine) 
The intensity and area of occurrence of these changes depends on the scale of the disjunctive. With all certainty, this zone can only be confirmed by developing. The results of numerical simulation should be accepted as the horizontal boundaries of the tectonically stressed zone.

The vertical boundary of the tectonically stressed zone is induced by the zero circuit of decay of the displacement amplitude along the discontinuous fault. The fact of wedging-out is confirmed by simulation data, exploration drilling and sinking. Zero circuits are currently set for all confirmed discontinuous faults.

Based on the results of the geodynamic zoning and transfer of the allocated block structures in the undeveloped part of the field rock mass, the boundaries of the block structures in the roof of the seams triple and fourth have been determined (figure 7).

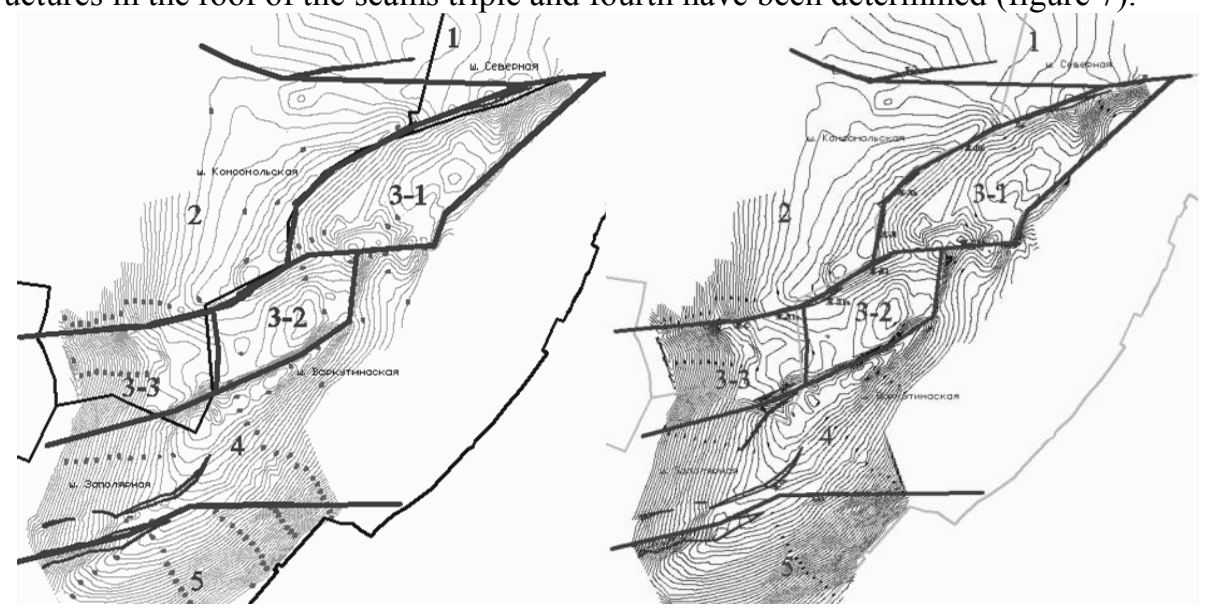

Fig. 7. Projection of tectonic blocks, allocated by the morphostructural method, in the central part of the trough on the hypsometric surface of the seam triple (right) and fourth (left).

The experience of performing geomechanical calculations based on the data of threedimensional and geodynamic simulation is actively used with respect to the coal deposits in Kuzbass. Zones with increased and reduced stress are allocated on the basis of the results of numerical simulation. Via compiling the results of geodynamic and numerical simulation for the mine named after V.D. Yalevsky, the obtained results are geometrized on mining plans. For example, it is possible to observe the process of converting from the unloaded to the stressed state.

For local assessing the distribution of main maximum stresses, the situation is simulated during the long-wall mining as of the mine face location. As shown in figures 8 and 9, the geomechanical situation is simulated as of the mine face location at $1300 \mathrm{~m}$ and $2000 \mathrm{~m}$ from the mounting chamber. 


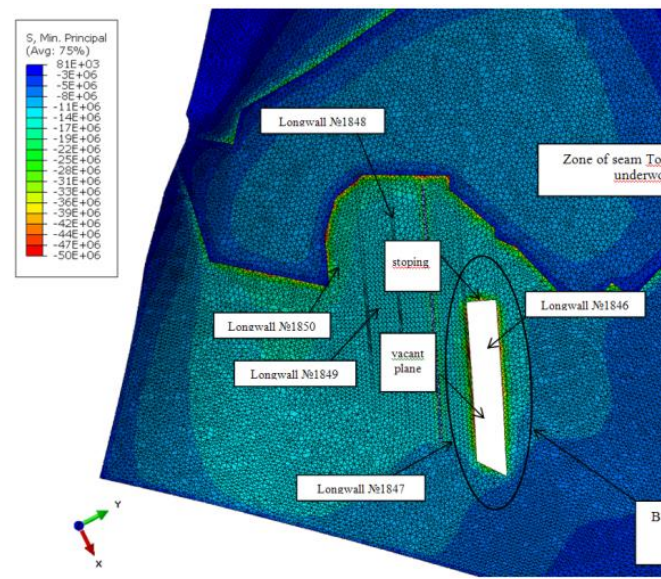

Fig. 8. Isochromes of the distribution of maximum stresses in the rock mass (1300 $\mathrm{m}$ from the mounting chamber)

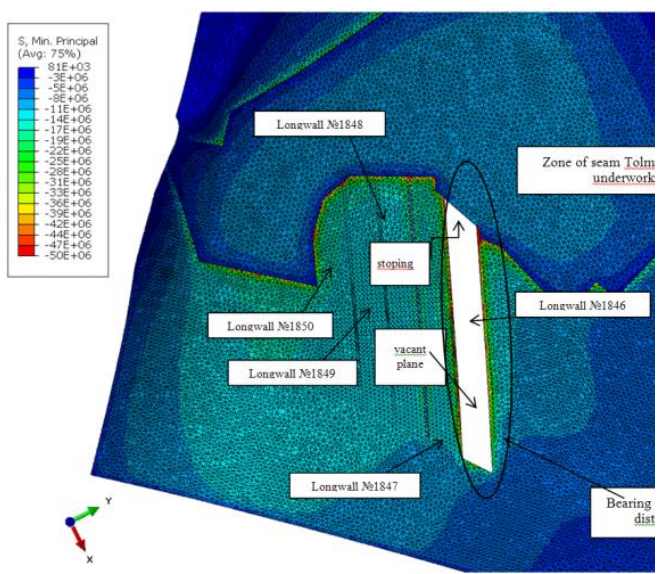

Fig. 9. Isochromes of the distribution of maximum stresses in the rock mass (2000 $\mathrm{m}$ from the mounting chamber)

As is seen from the figures above, the planned mining operations are initially located in the bearing pressure zone, which was formed as a result of the stopped excavation in the early stages. Main compression stresses in this part of the coal seam do not exceed 11-17 MPa. However, when approaching the underworking zone in the north part of the seam, the main stresses increase up to $42-46 \mathrm{MPa}$ in some sections of the rock mass.

During long-wall face advancing, the bearing pressure zone also begins to form near the excavation site. The mine's engineering services accept the design parameters of the bearing pressure zone, as well as the assumed values of stresses therein, however, upon the study results, these parameters were corrected.

The greatest main stresses in the rock mass during long-wall mining occur when approaching the underworking zone in the northern part of the seam. This area also coincides with the axial part of the brachysyncline, where maximum values of the stressed field form.

During further mining operations, upon the increase in the number of mining seams, the maximum quantitative values of the stresses will be concentrated in the solid between mining seams.

The stress values obtained by calculation, allowed the engineers at the enterprise to choose the optimal type of support in hazardous zones and calculate its parameters, thereby improving the efficiency of sinking and mining operations.

\section{Conclusion}

The studies conducted have shown that zones of active faults, both formed and being forming, carry a number of risks to a wide variety of ground facilities, buried structures and communications, from railways to deep mine workings. The greatest risk caused by the impact of faults takes place when developing deep, rock-bump hazardous coal and ore deposits. At the same time, awareness of the location of the faults and their characteristics makes it possible not only to reduce, but also more precisely outline the deposits, as well as to assess prospective reserves, choose most efficient methods for developing fields, preserving non-commercial reserves, etc.

Currently, the specific features of the impact of faults on various engineering structures are known only in the first approximation, due to the presence of many natural and manmade factors. 
Based on the results of applying a comprehensive approach to geodynamic zoning, its high efficiency was determined when developing coal fields under complex mining and geological conditions; the first reliable data were obtained using morphostructural analysis of coal seams hypsometry and measurements of the magnetic component of the alternating electromagnetic field, more reliable prediction of the parameters of potentially hazardous zones was made by using numerical simulation of the stress-strain state of coal rock mass.

\section{References}

1. I.Yu.Rasskazov, B.G.Saksin, V.I. Usikov, M.I. Potapchuk, Gornyi Zhurnal, Rock mass geodynamics and mining-induced rockbursting at Nikolaev complex deposit (2016)

2. A.S. Batugin, E3S Web of Conferences, Critically Stressed Areas of Earth's Crust as Medium for Man-caused Hazards (2018)

3. V.D. Baryshnikov, A.P. Khmelinin, D.V. Baryshnikov, IOP Conference Series: Earth and Environmental Science, Experimental assessment of stresses in enclosing rock mass of Aikhal mine (2019)

4. A.S. Voznesensky, Y.O. Kutkin, M.N. Krasilov, Journal of Mining Science, Interrelation of the acoustic Q-factor and strength in limestone (2015)

5. S.V. Suknev, Journal of Mining Science, Determination of elastic properties of rocks under varying temperature (2016)

6. A.S. Batugin GIAB - Miner's week, To the assessment of geodynamic risk, 11, 44 (2006)

7. A. V Lovchikov, Information and Analytical Bulletin, Rational classification of structural-block heterogeneity of rock mass for mines, 6, 226 (1999)

8. I.M. Petukhov, I.M. Batugina, Geodynamic zoning of subsurface resources (Methodical Guidelines, edited by. - L.: VNIMI, 1990)

9. A.N. Shabarov, N.V. Krotov, D.V. Sidorov, S.V. Tsirel, 21st World Mining Congress\&Expo, Modern Methods and Means for Solving Forecast Issues fnd Prevention of Geodynamic Phenomena in Collieries, 137 (2008)

10. V.V. Zubkov, Calculation of protected areas under the mutual influence of mine workings (VNIMI collected book 95, 1975)

11. K. S.Osasan, Open-cast mine slope deformation and failure mechanisms interpreted from slope radar monitoring, (PhD Thesis, Johannesburg, 2012)

12. V.V. Zubkov, I.A. Zubkova, E.E. Kvyatkovskaya, Mine surveying bulletin, On the construction of zones of high rock pressure when analyzing mining plans for a suite of coal seams, 1, 60 (2013)

13. Paul J.Melchior, The Tides of the Planet Earth. Oxford; (New York. Pergamon Press, 1978)

14. V.A. Shapiro, T.P. Korokina, The results of geomagnetic survey and re-leveling data correlation within the bounds of Ural geomagnetic site (In book: Present-day crustal motion. M.: Nauka, 1980)

15. V.A. Alekseev, I.G. Alekseeva, T.N. Bibikova, Problems of geology and subsurface development in the south of Russia. / Materials of international conference. Rostovon-Don, Identification of faults in the earth's crust and prediction of earthquakes through cloud observations, 44 (2006)

16. A. Dietrich,: Technical Report: Task 4.1: Definition of different damage processes in pipelines. (LIMATOG project document classification code: TRP_T4.1_(BB), First Draft. p. 1-4.) 
17. Yu.G. Kobylyansky, S.V. Tsirel, Geoenergetics. Geopolitics, Electronic scientific journal Geo-resources, The impact of faults on accidents in pipelines, 2 , http://oilgasjournal.ru/vol_2/articles/4.html

18. S.V. Tsirel, A.N. Shabarov, A.A. Prosvetova, Mining Information and Analytical Bulletin, Predictive assessment of the geodynamic hazard when planning mining operations, 4, 323 (2015)

19. Z.T. Bieniawski, Engineering rock mass classifications (New York, John Wiley \& Sons, 1989)

20. E. Villaescusa, Geotechnical Design for Sublevel Open Stoping. (New York, SRC Press, 2014)

21. V.A. Rudnik, E.K. Melnikov, Issues of ecological mineralogy and geochemistry, St. Petersburg, Geo-active zones (GAZ) and geochemical specialized complexes (GSC) dominant factor of life environment, 92 (1997)

22. A.I. Alekhin, Electronic journal "Issues of Ecology". - Donetsk, Faults as ecological risk zones, 1-2, http://masters.donntu.org/2011/feht/brilyova/library/stat4.htm

23. V.G. Trifonov, Neotectonics of Eurasia. (M.: Scientific world, 1999)

24. G.G. Kocharyan, V.I. Rodionov, A.L. Benedik et al. Geoecology, Influence of geodynamic factors on the mechanical stability of extended engineering structures. 6, 489 (2001). 